\title{
Relationship between Self-Esteem and Self-Consciousness in Adolescents: An Eye-Tracking Study
}

\author{
Eun Seong Kim ${ }^{1,2}$, Yeon-Ju Hong ${ }^{1}$, Minwoo Kim³ ${ }^{3}$ Eun Joo Kim, and Jae-Jin Kim ${ }^{1,5} \bowtie$ \\ ${ }^{1}$ Institute of Behavioral Science in Medicine, Yonsei University College of Medicine, Seoul, Republic of Korea \\ ${ }^{2}$ Department of Occupational Therapy, Chunnam Techno University, Gokseong, Republic of Korea \\ ${ }^{3}$ Yonsei University College of Medicine, Seoul, Republic of Korea \\ ${ }^{4}$ Yonsei University Graduate School of Education, Seoul, Republic of Korea \\ ${ }^{5}$ Department of Psychiatry, Yonsei University Gangnam Severance Hospital, Seoul, Republic of Korea
}

\begin{abstract}
Objective Self-esteem and self-consciousness are important determinants of behaviors. This study aimed to explore the relationship between self-esteem and self-consciousness in adolescents using the eye-tracking measurement.

Methods Fifty-five adolescents with high self-esteem and 58 adolescents with low self-esteem participated in self-consciousness-related eye-tracking experiments of selecting happy, disgusted, and angry facial emotions while recognizing one's own usual expressions and the others' usual expressions toward oneself.

Results When recognizing one's own, adolescents with high self-esteem showed significantly more selection counts and longer fixation time for 'happy' than adolescents with low self-esteem. When recognizing the others', adolescents with low self-esteem showed significantly more selection counts and longer fixation time for 'disgusted' and 'angry' than adolescents with high self-esteem.

Conclusion These suggest higher self-esteem is connected to more positive identification of one's usual expressions and others' usual expressions toward oneself. There is a close relationship among low self-esteem, suppressing positive emotions, decreased psychological adjustment, and increased negative emotions.

Psychiatry Investig 2019;16(4):306-313
\end{abstract}

Key Words Self-esteem, Self-consciousness, Facial emotions, Eye-tracking, Adolescence.

\section{INTRODUCTION}

Adolescence is a transition period accompanied by physical, psychological, and social changes that cause emotional awakening, and thus it is a time when emotion regulation is the most challenging. ${ }^{1,2}$ Emotional experience in this period is stronger than in any time in life. Emotional control at this time is related to social and emotional development, academic achievement, attention-concentration, prosocial behavior, problem-solving ability, interpersonal quality, and physical health, ${ }^{3}$ and its problem is linked to maladaptive behaviors and maladjustment. ${ }^{4}$

\footnotetext{
Received: August 14, 2018 Revised: October 25, 2018

Accepted: February 10, 2019

$\triangle$ Correspondence: Jae-Jin Kim, MD, PhD

Department of Psychiatry, Yonsei University Gangnam Severance Hospital, 211 Eonju-ro, Gangnam-gu, Seoul 06273, Republic of Korea

Tel: +82-2-2019-3341, Fax: +82-2-3462-4304, E-mail: jaejkim@yonsei.ac.kr

(c) This is an Open Access article distributed under the terms of the Creative Commons Attribution Non-Commercial License (https://creativecommons.org/licenses/bync/4.0) which permits unrestricted non-commercial use, distribution, and reproduction in any medium, provided the original work is properly cited.
}

Emotion is one of determinants of self-esteem. In particular, the specificity of adolescents' attachment to parents and peers plays an important role in forming teenagers' self-esteem. ${ }^{5}$ Adolescents with high self-esteem have positive feelings about their lives such as cheerfulness, vigor, sense of security, confidence in the future, and realistic expectation of self, whereas those with low self-esteem often feel emotionally depressed. ${ }^{6}$ Self-esteem is crucial to individuals' psychological well-being, and the level of self-esteem can affect individuals' sense of happiness in their lives.

It has been considered that self-esteem has a consistent influence on the identity styles. ${ }^{8}$ Ideal self-esteem can be achieved through personal and subjective experiences, not by success in an external domain in which the eye of others is conscious. ${ }^{9}$ In terms of social identity theory, an individual's healthy selfconcept derives from the harmonious perception of independent personal self and interdependent self. ${ }^{10}$ Self-esteem is closely related to human relationships, and varies depending on how likely it is that one is rejected by another. ${ }^{11}$ People with high self-esteem tend to make interpersonal relationships 
more pleasant by making cognitive beneficial interpretations even under negative circumstances, whereas those with low self-esteem are more likely to misinterpret events and to negatively affect the formation of interpersonal relationships. ${ }^{12}$

Given that emotion provides crucial information about the significance of social situations, ${ }^{13}$ being aware of one's own and others' emotions is essential for adapting to a social environment. Emotion awareness is the ability to recognize and appreciate the importance of emotions in oneself and others, ${ }^{14}$ and involves a willingness to face one's own and others' emotions. ${ }^{15}$ The ability to interpret and regulate one's own emotions is an important factor in social adaptive behaviors. ${ }^{16}$ The ability to accurately perceive and respond to others' emotions including facial expressions is also crucial for social adaptation and interpersonal relationships. ${ }^{17,18}$ Individuals with a clear perception of emotion tend to be more active in seeking social support and more satisfied with universal life. ${ }^{19,20}$ On the contrary, those who lack emotion awareness show more internalization problems such as depression and somatization. ${ }^{21}$

The relationship between emotion and self-esteem has been an interesting subject in the studies of the interpersonal relationships. For example, self-face evaluation and self-esteem show a closely interrelated relationship, which was mediated by the posterior cingulate cortex and ventral tegmental area. ${ }^{22}$ In a previous study that examined eye movement to identify the effects of self-esteem on face recognition, individuals with high self-esteem paid more attention to self-face, whereas those with low self-esteem paid more attention to others. ${ }^{23}$ In addition, it has been shown that emotion dysregulation mediates the association of low self-esteem level with physical aggression, anger, and hostility. ${ }^{24}$ While most of these previous studies have focused on emotional recognition or regulation, the effects of self-esteem on self-consciousness have not been sufficiently studied yet.

Self-consciousness refers to the extent to which people direct attention inward or outward and is an important behavioral determinant of social interaction. ${ }^{25}$ Previous studies have shown that negatively valenced appearance is related to increased self-consciousness. ${ }^{26,27}$ The level of self-consciousness is closely related to satisfaction of the interpersonal relationship $^{28}$ and the relationship between perceived norms and addictive behavior. ${ }^{29}$ Self-consciousness has been considered to have three prominent facets: private/public aspects, adaptive/ maladaptive applied characteristics, and present/past experiences. ${ }^{30}$ In particular, private self-consciousness is a tendency to introspect and examine one's inner self and feelings, whereas public self-consciousness is an awareness of the self as it is viewed by others. ${ }^{25}$ Facial expressions provide the most prominent clues about the emotional state of others, and people use facial expressions to adjust their behavior and determine their attitudes toward others. ${ }^{31}$ Therefore, facial expressions can be a useful tool for the exploration of private and public selfconsciousness.

A purpose of this study was to investigate the relationship between self-esteem and self-consciousness in adolescents. Specifically, we examined a difference of eye-tracking movements in recognizing one's own facial expressions and recognizing the others' facial expressions toward oneself between the high and low self-esteem adolescent groups. In this study, our hypothesis was that the high self-esteem group would more positively identify their usual facial expressions and also more positively evaluate others' facial expressions, compared to the low self-esteem group.

\section{METHODS}

\section{Participants}

The Korean version ${ }^{32}$ of the Rosenberg self-esteem scale s $^{33}$ was administered to 573 second-year students (16 years old; 209 males and 364 females) in two high schools in South Korea to screen out a total of 60 male and 60 female adolescents in the upper and lower percentiles of the self-esteem scores. The scores ranged from 35 to 40 points (referred to as "High SE group") and from 17 to 28 points (referred to as "Low SE group"), respectively, and corresponded to the upper and lower $13^{\text {th }}$ percentiles in male adolescents and $8^{\text {th }}$ percentiles in female adolescents. They were subjected to a behavioral experiment and the assessment of additional questionnaires. After excluding those with eyesight problems and with missing responses, a total of 55 male adolescents (27 in High SE group, 28 in Low SE group) and 58 female adolescents (28 in High SE group, 30 in Low SE group) were included in the analysis. This study has been approved by the local Institutional Review Board Committee (3-2014-0257), and all participants signed a written informed consent.

\section{Psychological assessments}

The Beck Depression Inventory (BDI), ${ }^{34}$ the Satisfaction with Life Scale (SWLS), ${ }^{35}$ and Basic Psychological Needs Scale $(\mathrm{BPNS})^{36}$ were assessed to examine the level of depression, life satisfaction, and self-determination (autonomy, competence, and relatedness), respectively. The NEO Personality Inventory (NEO-PI-R) ${ }^{37}$ was applied to evaluate five personality traits (extroversion, agreeableness, openness, neuroticism, Conscientiousness). Meanwhile, to confirm that there is no group difference in the level of intelligence, the Raven's Progressive Matrices (RPM) $)^{38}$ was assessed.

\section{Behavioral tasks}

We developed a self-consciousness task for eye-movement 
tracking, in which an experimental stimulus of each trial was comprised of 6 strangers' faces (Figure 1). The faces were those of happy male, disgusted male, angry male, happy female, disgusted female, and angry female, which were placed in a hexagonal position. They were presented for 5 seconds, and then replaced with boxes in the same position. The boxes were presented for 2 seconds for participants to respond using a corresponding button in the keyboard following the instruction. A fixation cross was followed for the stimulus interval of $0.5 \mathrm{sec}-$ onds. There are two experiments according to the instructions, which were "Choose which picture resembles the most closely your usual facial expression" in the experiment 1 and "Choose which picture resembles the most closely others' usual facial expression toward you" in the experiment 2. Participants' task was to select one of the faces by pressing the corresponding button. An experiment consisted of twenty trials of $7.5 \mathrm{sec}-$ onds, taking a total of 150 seconds. The position of the faces was randomly arranged in the series of trials. The face stimuli used in the task were selected from the Korean Facial Expressions of Emotion. ${ }^{39}$

\section{Eye movement recording}

While participants performed the tasks, eye movements were recorded using the SensoMotoric Instrument (SMI, Boston, USA) eye movement monitoring system. Participants' eye position was maintained at a distance of approximately $50 \mathrm{~cm}$ from the monitor. Before the experiment, participants were instructed to fix their gaze at several dots to calibrate their eye movements. The sampling rate of eye gaze during the measurement was $120 \mathrm{~Hz}$. The gaze data were analyzed with SMI BeGaze. A fixation was counted when participants gazed at the monitor within an area of 100 pixels for more than $80 \mathrm{~ms}$. The area of interest (AOI) was defined as a box drawn around the stimulus face. The rate of fixation in the AOI was calculated for each subject and stimulus. Among 6 AOIs, data from the male and female faces with the same emotion were averaged, and thus the fixation time was counted for AOIs with 3 emotions, such as 'happy', 'disgusted', and 'angry'.

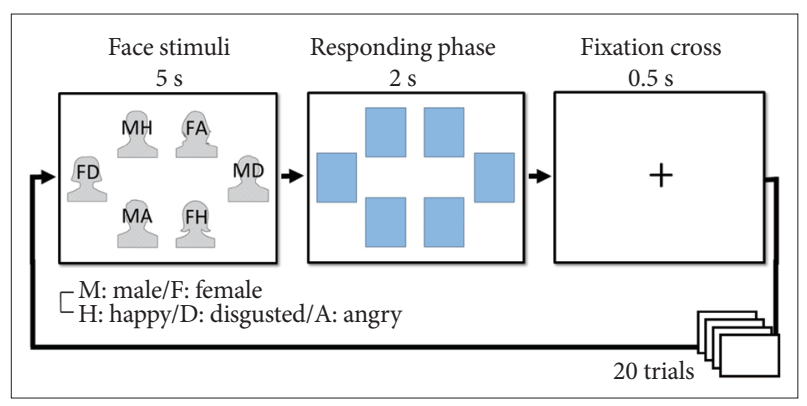

Figure 1. Behavioral task procedure.

\section{Statistical analysis}

Demographic data and scale scores were compared between the two groups using independent-sample t-tests, except for sex, which was analyzed using chi-square test. The selection count and fixation time in each experiment were analyzed with a linear mixed model to identify the main effects and interactions of group and facial emotion. Associations of the fixation time with the selection counts and scale scores in each group were examined with Pearson correlation analysis. Considering that there were three facial emotions in all analyses, a significance threshold was defined at $\mathrm{p}<0.017$ $(0.05 / 3)$.

\section{RESULTS}

\section{Psychological assessments}

As shown in Table 1, the RSES scores were $38.02 \pm 1.78$ in the high SE group and $23.84 \pm 2.71$ in the low SE group, and were significantly different between the two groups $(p<0.001)$. All participants have the same age, and the two groups showed no difference in gender distribution and cognitive ability measured by the RPM. The BDI scores were significantly lower in the high SE group than in the low SE group $(\mathrm{p}<0.001)$. The high SE group showed significantly higher scores in satisfaction with life, autonomy, competence, and relatedness than the low SE group (all: $\mathrm{p}<0.001$ ). In the NEO-PI-R, the high SE group showed significantly higher scores in extroversion $(\mathrm{p}<$ $0.001)$, agreeableness $(\mathrm{p}=0.001)$, conscientiousness $(\mathrm{p}<0.001)$, and openness $(\mathrm{p}<0.001)$, but significantly lower in neuroticism $(\mathrm{p}<0.001)$ than the low SE group.

\section{Task performance}

The results of selection counts are shown in Table 2. The results were very similar between Experiment 1 and 2. In both experiments, most of the high SE group seldom chose 'disgusted' or 'angry', whereas a sizable number of the low SE group chose 'disgusted' and 'angry'. The selection counts showed the main effect of emotion (Experiment 1: $\mathrm{F}_{2,11}=528.18, \mathrm{p}<0.0001$; Experiment 2: $\mathrm{F}_{2,11}=590.96, \mathrm{p}<0.0001$ ), but there was no main effect of group. Post-hoc test showed that the selection counts were significantly higher for 'happy' than for 'disgusted' and 'angry' (all: $\mathrm{p}<0.0001$ ), but there was no difference between 'disgusted' and 'angry'. The interaction effect of group x emotion was significant (Experiment 1: $\mathrm{F}_{2,111}=15.46, \mathrm{p}<0.0001$; Experiment 2: $\left.\mathrm{F}_{2,11}=12.42, \mathrm{p}<0.0001\right)$. Post-hoc test showed that the selection counts of 'happy' were significantly higher in the high SE group than in the low SE group, whereas those of 'disgusted' and 'angry' were significantly higher in the low SE group than in the high SE group (all: $\mathrm{p}<0.0001$ ). 
Table 1. Characteristics of participants

\begin{tabular}{|c|c|c|c|c|}
\hline \multirow{2}{*}{ Characteristic } & \multicolumn{2}{|c|}{ Self-esteem group } & \multirow{2}{*}{$\mathrm{t} / \chi^{2}$} & \multirow{2}{*}{$\mathrm{p}$-value } \\
\hline & High group $(\mathrm{N}=55)$ & Low group $(\mathrm{N}=58)$ & & \\
\hline Rosenberg self-esteem scale & $38.02 \pm 1.78$ & $23.84 \pm 2.71$ & 33.05 & $<0.001$ \\
\hline Male/female & $27 / 28$ & $28 / 30$ & $0.01^{*}$ & 0.931 \\
\hline Raven's progressive matrices & $50.71 \pm 8.18$ & $49.24 \pm 7.79$ & 0.98 & 0.331 \\
\hline Beck depression inventory & $3.91 \pm 3.04$ & $13.28 \pm 6.10$ & -10.41 & $<0.001$ \\
\hline Satisfaction with life scale & $22.78 \pm 4.08$ & $13.81 \pm 3.87$ & 11.99 & $<0.001$ \\
\hline \multicolumn{5}{|l|}{ Basic psychological needs scale } \\
\hline Autonomy & $31.42 \pm 3.96$ & $23.83 \pm 5.24$ & 8.72 & $<0.001$ \\
\hline Competence & $30.40 \pm 3.37$ & $20.90 \pm 4.61$ & 12.45 & $<0.001$ \\
\hline Relatedness & $32.80 \pm 3.39$ & $25.84 \pm 4.16$ & 9.71 & $<0.001$ \\
\hline \multicolumn{5}{|l|}{ NEO-personality inventory } \\
\hline Extroversion & $7.29 \pm 1.62$ & $6.07 \pm 1.53$ & 4.12 & $<0.001$ \\
\hline Agreeableness & $7.91 \pm 1.54$ & $6.95 \pm 1.43$ & 3.43 & 0.001 \\
\hline Conscientiousness & $6.95 \pm 1.94$ & $4.38 \pm 1.67$ & 6.24 & $<0.001$ \\
\hline Neuroticism & $4.96 \pm 1.64$ & $6.86 \pm 1.63$ & -6.17 & $<0.001$ \\
\hline Openness & $8.36 \pm 1.70$ & $7.24 \pm 1.84$ & 3.36 & $<0.001$ \\
\hline
\end{tabular}

*chi-square for categorical variable

Table 2. Selection counts out of 20 trials during the self-consciousness task

\begin{tabular}{|c|c|c|c|c|}
\hline \multirow{2}{*}{ Facial emotion } & \multicolumn{2}{|c|}{ Self-esteem group } & \multirow{2}{*}{$\mathrm{t}$} & \multirow{2}{*}{$\mathrm{p}$-value } \\
\hline & High group $(\mathrm{N}=55)$ & Low group $(\mathrm{N}=58)$ & & \\
\hline \multicolumn{5}{|c|}{ Experiment 1: own usual facial expression } \\
\hline Happy & $19.13 \pm 1.88$ & $14.14 \pm 6.36$ & 5.72 & $<0.001$ \\
\hline Disgusted & $0.35 \pm 0.80$ & $1.97 \pm 2.46$ & -4.76 & $<0.001$ \\
\hline Angry & $0.40 \pm 1.21$ & $3.60 \pm 4.31$ & -5.44 & $<0.001$ \\
\hline \multicolumn{5}{|c|}{ Experiment 2: others facial expression toward oneself } \\
\hline Happy & $19.24 \pm 1.57$ & $15.69 \pm 5.04$ & 5.10 & $<0.001$ \\
\hline Disgusted & $0.36 \pm 0.82$ & $1.83 \pm 2.23$ & -4.67 & $<0.001$ \\
\hline Angry & $0.38 \pm 1.03$ & $2.34 \pm 3.19$ & -4.45 & $<0.001$ \\
\hline
\end{tabular}

\section{Eye-tracking data}

Experiment 1 (Figure 2A): when selecting the face that the most closely resembled one's own usual facial expressions, the fixation time showed the main effect of facial emotion $\left(\mathrm{F}_{2,11}=\right.$ 126.94, $p<0.0001$ ), but no main effect of group. In the post-hoc test, the fixation time was significantly shorter for 'disgusted' $(\mathrm{p}<0.0001)$ and 'angry' $(\mathrm{p}<0.0001)$ than 'happy.' The interaction effect of group $\mathrm{x}$ facial emotion was significant $\left(\mathrm{F}_{2,111}=10.77\right.$, $\mathrm{p}<$ 0.0001). The fixation time for 'happy' was not significantly different between the two groups, but those for 'disgusted' and 'angry' were significantly longer in the low SE group than in the high SE group ( $\mathrm{p}=0.019$ and 0.004 , respectively).

Experiment 2 (Figure 2B): when selecting the face that the most closely resembled others' facial expressions toward oneself, the fixation time showed the main effect of facial emotion
$\left(\mathrm{F}_{2,11}=151.47, \mathrm{p}<0.0001\right)$, but no main effect of group. In the post-hoc test, the fixation time was significantly shorter for 'disgusted' ( $\mathrm{p}<0.0001)$ and 'angry' ( $\mathrm{p}<0.0001)$ than 'happy.' The interaction effect of group $\mathrm{x}$ facial emotion was significant $\left(\mathrm{F}_{2,111}=15.52, \mathrm{p}<0.0001\right)$. The fixation time for 'happy' was significantly shorter in the low SE group than in the high SE group $(\mathrm{p}<0.0001)$, but those of 'disgusted' and 'angry' were not significantly different between the two groups.

\section{Correlations between the selection count and fixation time (Table 3)}

Experiment 1: the fixation time and selection count showed no correlation for all facial emotions in the high SE group, but they showed a positive correlation for 'happy' $(\mathrm{r}=0.54, \mathrm{p}<0.001)$ and 'disgusted' $(r=0.38, p<0.01)$ in the low SE group. 
Experiment 2: in the high SE group, the fixation time and selection count showed a positive correlation for 'angry' ( $\mathrm{r}=$ $0.33, \mathrm{p}=0.014$ ), but no correlation for 'happy' and 'disgusted. In the low SE group, they showed a positive correlation for 'happy' $(\mathrm{r}=0.39, \mathrm{p}<0.01)$, but no correlation for 'disgusted' and 'angry'.

\section{Correlations between the psychological scale score and fixation time (Table 3)}

Experiment 1: in the high SE group, the significant results were the negative correlations between the autonomy scores and fixation time for 'disgusted' ( $\mathrm{r}=-0.39, \mathrm{p}<0.01)$ and 'angry'
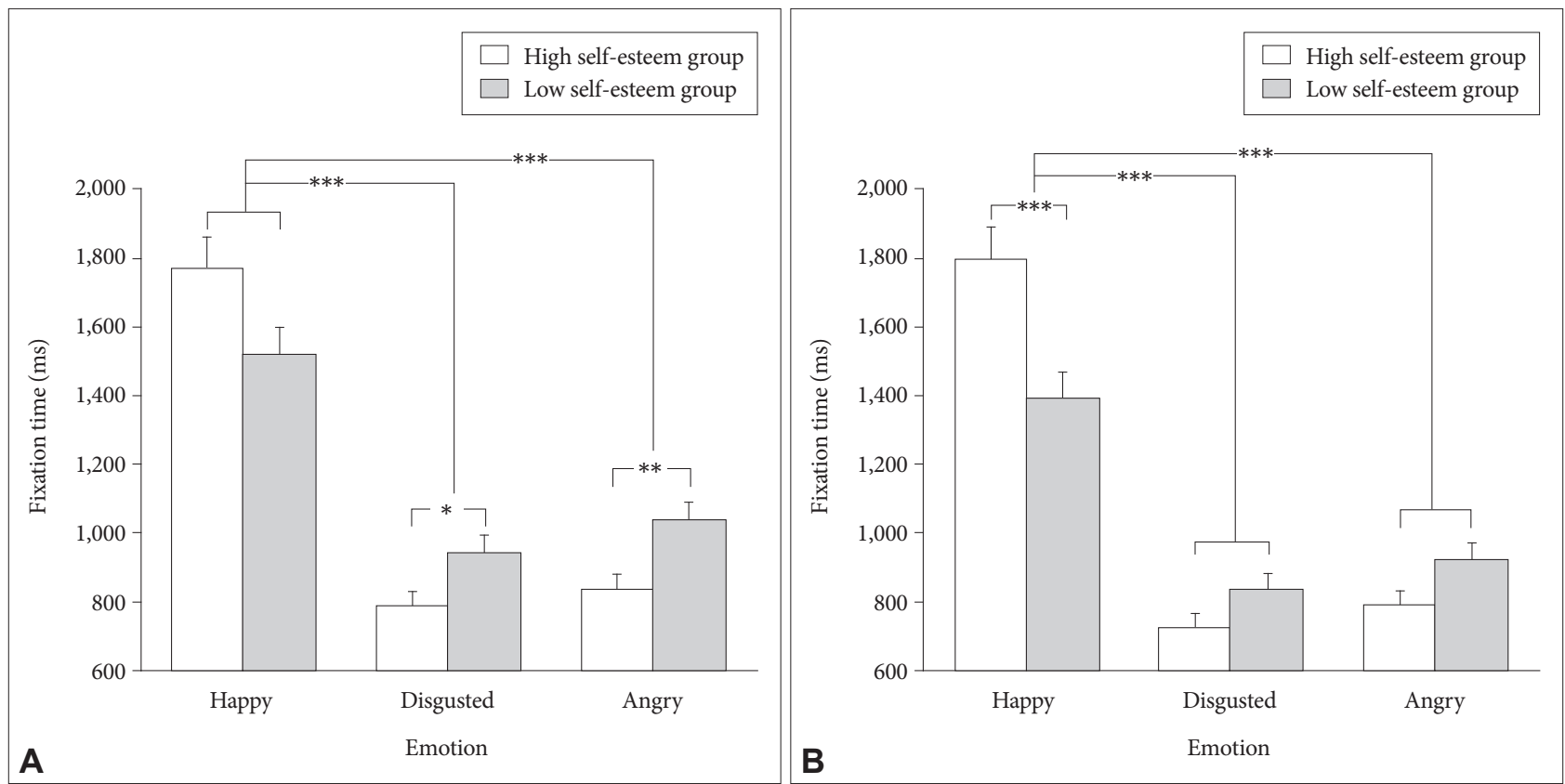

Figure 2. Group comparison of the fixation time for the happy, disgusted, and angry faces. A: One's own usual facial expressions. B: Others' facial expressions toward oneself. ${ }^{*} p<0.05,{ }^{* *} p<0.01,{ }^{* *} p<0.001$.

Table 3. Correlations of the fixation time with the behavioral responses and scale scores

\begin{tabular}{|c|c|c|c|c|c|c|c|c|c|c|c|c|}
\hline & \multicolumn{12}{|c|}{ Fixation time } \\
\hline & \multicolumn{6}{|c|}{ Experiment 1 (own) } & \multicolumn{6}{|c|}{ Experiment 2 (other) } \\
\hline & \multicolumn{3}{|c|}{ High SE group } & \multicolumn{3}{|c|}{ Low SE group } & \multicolumn{3}{|c|}{ High SE group } & \multicolumn{3}{|c|}{ Low SE group } \\
\hline & $\mathrm{H}$ & $\mathrm{D}$ & $\mathrm{A}$ & $\mathrm{H}$ & $\mathrm{D}$ & $\mathrm{A}$ & $\mathrm{H}$ & $\mathrm{D}$ & $\mathrm{A}$ & $\mathrm{H}$ & $\mathrm{D}$ & $\mathrm{A}$ \\
\hline \multicolumn{13}{|l|}{ Selection count } \\
\hline $\mathrm{H}$ & 0.30 & - & - & $0.54^{* * *}$ & - & - & 0.21 & - & - & $0.39^{* * *}$ & - & - \\
\hline $\mathrm{D}$ & - & 0.17 & - & - & $0.38^{* *}$ & - & - & 0.15 & - & - & 0.14 & - \\
\hline A & - & - & -0.04 & - & - & 0.30 & - & - & $0.33^{*}$ & - & - & 0.27 \\
\hline \multicolumn{13}{|l|}{ Scale score } \\
\hline $\mathrm{BDI}$ & 0.07 & 0.12 & 0.26 & $-0.40^{* *}$ & 0.08 & 0.11 & -0.09 & 0.15 & 0.26 & -0.21 & 0.06 & 0.06 \\
\hline Satisfaction with life & -0.05 & -0.22 & -0.28 & 0 & -0.29 & -0.28 & -0.15 & -0.28 & -0.19 & 0.05 & -0.06 & -0.05 \\
\hline Autonomy & -0.23 & $-0.39^{* *}$ & $-0.38^{* *}$ & 0.13 & -0.20 & -0.28 & -0.15 & -0.31 & -0.31 & 0.07 & -0.04 & 0.01 \\
\hline Competence & 0.05 & -0.29 & -0.34 & 0.19 & -0.23 & -0.23 & -0.13 & $-0.48^{* *}$ & $-0.51^{* *}$ & 0.13 & -0.04 & -0.04 \\
\hline Relatedness & -0.13 & $-0.37^{* *}$ & $-0.39^{* *}$ & 0.31 & -0.18 & -0.22 & -0.02 & -0.12 & -0.12 & 0.29 & 0.19 & 0.16 \\
\hline Extroversion & -0.08 & -0.11 & -0.13 & -0.11 & -0.01 & 0.01 & 0.29 & 0.09 & 0.1 & 0.03 & 0.2 & 0.15 \\
\hline Agreeableness & 0.03 & -0.1 & -0.07 & 0.07 & -0.12 & -0.13 & -0.09 & -0.21 & -0.27 & -0.02 & -0.09 & -0.03 \\
\hline Conscientiousness & 0.2 & -0.06 & -0.11 & 0.22 & -0.03 & 0 & 0.04 & -0.32 & -0.28 & 0.24 & -0.02 & -0.03 \\
\hline Neuroticism & -0.05 & 0.09 & 0.18 & -0.01 & -0.11 & -0.11 & 0.06 & 0.16 & 0.12 & 0 & -0.06 & 0 \\
\hline Openness & -0.08 & 0 & 0.03 & -0.03 & 0.07 & 0.08 & $0.33^{*}$ & 0.14 & 0.22 & 0.11 & 0.14 & 0.13 \\
\hline
\end{tabular}

${ }^{*} \mathrm{p}<0.05,{ }^{* *} \mathrm{p}<0.01,{ }^{* * *} \mathrm{p}<0.001$. SE: self-esteem, H: happy, D: disgusted, A: angry, BDI: Beck Depression Inventory 
$(\mathrm{r}=-0.38, \mathrm{p}<0.01)$, and between the relationship scores and fixation time for 'disgusted' ( $\mathrm{r}=-0.37, \mathrm{p}<0.01)$ and 'angry' $(\mathrm{r}=$ $-0.39, \mathrm{p}<0.01)$. In the low $\mathrm{SE}$ group, the only significant result was the negative correlation between the BDI scores and fixation time for 'happy' $(\mathrm{r}=-0.40, \mathrm{p}<0.01)$.

Experiment 2: in the high SE group, the positive correlation was found only between the openness score and fixation time for 'happy' ( $r=0.33, r=0.015)$, whereas the negative correlations were found between the competence score and fixation time for 'disgusted' $(\mathrm{r}=-0.48, \mathrm{p}<0.001)$ and 'angry' $(\mathrm{r}=-0.51, \mathrm{p}<0.001)$. In the low SE group, there was no significant correlation between the scale score and fixation time.

\section{DISCUSSION}

In this study the relationship between self-esteem and selfconsciousness was investigated in adolescents using the two separate experiments of recognizing one's own facial expressions and the others' facial expressions toward oneself. The selection counts in both experiments were very similar. Although a difference of the fixation time between the high and low SE groups was significant only for 'disgusted' and 'angry' when recognizing one's own facial expressions and only for 'happy' when recognizing the others' facial expressions toward oneself, the overall patterns of the fixation time in both experiments were also similar. Therefore, it seems that the effects of self-esteem on self-consciousness have a similarity between the private and public ones.

In the selection counts, most of the high SE group chose 'happy', suggesting that adolescents who have high self-esteem tend to pay attention to positive emotions much more than negative emotions. This feature was confirmed in the fixation time, which was far longer for 'happy' than for 'disgusted' and 'angry', suggesting that an adolescent with high self-esteem may look at himself or herself desirable. These results are consistent with previous findings that individuals with high selfesteem had more stability as well as positive emotions and lower emotional changes than those with low self-esteem. ${ }^{40}$ Selfesteem theory has predicted that the higher an individual's self-evaluation, the less reciprocation of evaluations from others. ${ }^{41}$ In particular, this group showed that the fixation time for 'disgusted' and 'angry' were negatively correlated with the autonomy and relatedness scores in Experiment 1 and the competence scores in Experiment 2, suggesting that the more self-determination of an individual may be linked to the less negative view of himself or herself. These correlations may be consistent with the argument that a person who is satisfied with autonomy, competence, and relatedness grows pro-social tendency. ${ }^{42}$ Meanwhile, the selection count and fixation time for 'happy' were significantly correlated in the low SE group, but not in the high SE group. This group difference may be attributed to the ceiling effect of these responses to happy emotion in the high SE group.

In the selection counts, a sizable number of the low SE group chose 'disgusted' and 'angry' rather than 'happy'. These features were confirmed in the eye-tracking measurement, which showed that the fixation times for 'disgusted' and 'angry' were significantly longer in the low SE group than in the high SE group. These results suggest that adolescents with low self-esteem tend to negatively recognize their own facial expressions and the others' facial expressions toward themselves. It has been demonstrated that lower self-esteem is correlated with more negative emotions and higher public self-consciousness. ${ }^{43}$ Relationships between suppression of positive emotions and selfesteem adjustment are mediated by a negative affect. ${ }^{44}$ The underlying discrepant state of self-consciousness may contribute to their increased negative affect in the low SE group. It should be considered, for example, that self-awareness tasks increased negative affect among participants with low explicit and high implicit self-esteem. ${ }^{45}$

Furthermore, in the low SE group, the fixation time for 'happy' was inversely correlated with the depression score. Low self-esteem in adolescence has been considered to be a predictor of the development of depression in early adulthood. ${ }^{46}$ Recent longitudinal studies have also demonstrated that sustained or worsening disordered behaviors and low self-esteem in adolescents are precursors of depressive symptoms. ${ }^{47,48} \mathrm{It}$ should be noted that depression in adolescence has been associated with negative attributional style, limited interpersonal relationships, increased likelihood of social isolation, and overall maladjustment as well as low self-esteem. ${ }^{49-51}$ In addition, lower self-esteem and negative emotions in adolescents sequentially mediate the relationship between body dissatisfaction and disordered eating. ${ }^{52}$ Taken together, there is a close relationship among low self-esteem, suppressing positive emotions, decreased psychological adjustment, and increased negative emotions. Given this relationship, it is important to identify adolescents at risk for depression. Our self-conscious task may be useful to screen them in need of early interventions.

The low SE group showed significant differences in all basic psychological needs components and personality domains compared with the high SE group. However, basic psychological needs components were inversely correlated with the fixation time for negative emotions in the high SE group, whereas there were no correlations between the personality types and fixation time in both groups. These results suggest that selfconscious behaviors are related to basic psychological needs rather than personality types. According to the self-determination theory, positive emotion is merely a by-product of need satisfaction and all forms of mental health are ultimately sup- 
ported by psychological need satisfaction..$^{53}$ The satisfaction of typical basic psychological needs is also crucial for experiencing wellbeing and esteem for one's community. ${ }^{54}$

This study had a few limitations despite the meaningful results above. First, academic achievement is an important factor for investigating self-esteem in high school students. ${ }^{55} \mathrm{Be}-$ cause all participants were school students, they may have been gravely impacted by academic achievement; however, this parameter was not included in the analysis. Second, although the levels of self-esteem can differ between male and female adolescents, ${ }^{56}$ this difference was not analyzed because it was not a focus in this study. Third, all participants were second-year students in Korean high schools. An age variation in adolescence and a cultural difference in cognitive self-evaluations ${ }^{57}$ could not be analyzed in this study.

In summary, we studied the relationship between self-esteem and self-consciousness in adolescents using eye-tracking measures for one's own facial expressions and the others' facial expressions toward oneself, and found that higher self-esteem was connected to more positive identification of their usual facial expressions and others' facial expressions. Furthermore, the fixation time for 'happy' was inversely correlated with the depression score in adolescents with low self-esteem, suggesting that low self-esteem is associated with depressive behaviors in adolescence. Given that low self-esteem in adolescence are precursors of depressive symptoms, our self-conscious task may be used to identify adolescents at risk for depression and in need of appropriate interventions. Forwards, many types of research are needed to be done on emotional identification on self to know how to promote and maintain selfesteem in adolescents, which is the ultimate aim.

\section{Acknowledgments}

This work was supported by the National Research Foundation of Korea (NRF) grant funded by the Korea government (MSIP) (No. NRF-2016R1A 2A2A10921744).

\section{Conflicts of Interest}

The authors have no potential conflicts of interest to disclose.

\section{Author Contributions}

Conceptualization: Eun Seong Kim, Jae-Jin Kim. Data acquisition: Eun Seong Kim, Yeon-Ju Hong, Minwoo Kim. Formal analysis: Eun Seong Kim. Funding: Jae-Jin Kim. Supervision: Eun Joo Kim. Writing_original draft: Eun Seong Kim. Writing—review \& editing: Eun Joo Kim, Jae-Jin Kim.

\section{ORCID iDs}

\section{Jae-Jin Kim}

Eun Seong Kim

https://orcid.org/0000-0002-1395-4562

https://orcid.org/0000-0002-3216-3627

\section{REFERENCES}

1. Hare TA, Tottenham N, Galvan A, Voss HU, Glover GH, Casey B. Biological substrates of emotional reactivity and regulation in adolescence during an emotional go-nogo task. Biol Psychiatry 2008;63:927-934.
2. Silk JS, Steinberg L, Morris AS. Adolescents' emotion regulation in daily life: Links to depressive symptoms and problem behavior. Child Dev 2003;74:1869-1880.

3. Repetti RL, Taylor SE, Seeman TE. Risky families: family social environments and the mental and physical health of offspring. Psychol Bull 2002;128:330-366.

4. Cole PM, Martin SE, Dennis TA. Emotion regulation as a scientific construct: methodological challenges and directions for child development research. Child Dev 2004;75:317-333.

5. Sadovnikova T. Self-esteem and interpersonal relations in adolescence. Procedia Soc Behav Sci 2016;233:440-444.

6. Rogers CR. Toward a science of the person. J Humanist Psychol 1963; 3:72-92.

7. Furnham A, Cheng H. Perceived parental behaviour, self-esteem and happiness. Soc Psychiatry Psychiatr Epidemiol 2000;35:463-470.

8. Soenens B, Berzonsky MD, Papini DR. Attending to the role of identity exploration in self-esteem: longitudinal associations between identity styles and two features of self-esteem. Intern J Behav Dev 2016;40:420430 .

9. Kernis MH. Toward a conceptualization of optimal self-esteem. Psychol Inq 2003;14:1-26.

10. Markus HR, Kitayama S. Culture and the self: implications for cognition, emotion, and motivation. Psychol Rev 1991;98:224-253.

11. Leary MR, Tambor ES, Terdal SK, Downs DL. Self-esteem as an interpersonal monitor: the sociometer hypothesis. J Pers Soc Psychol 1995; 68:518-530.

12. Murray SL, Holmes JG, Collins NL. Optimizing assurance: the risk regulation system in relationships. Psychol Bull 2006;132:641-666.

13. Barrett LF, Gross J, Christensen TC, Benvenuto M. Knowing what you're feeling and knowing what to do about it: mapping the relation between emotion differentiation and emotion regulation. Cogn Emot 2001;15: 713-724.

14. Rieffe C, Oosterveld P, Miers AC, Terwogt MM, Ly V. Emotion awareness and internalising symptoms in children and adolescents: the Emotion Awareness Questionnaire revised. Pers Indiv Differ 2008;45:756761.

15. Ochsner KN, Gross JJ. The cognitive control of emotion. Trends Cogn Sci 2005;9:242-249.

16. Lopes PN, Salovey P, Cata S, Beers M. Emotion regulation abilities and the quality of social interaction. Emotion 2005;5:113-118.

17. Lopes PN, Brackett MA, Nezlek JB, Schatz A, Sellin I, Salovey P. Emotional intelligence and social interaction. Pers Soc Psychol Bull 2004; 30:1018-1034.

18. Pinkham AE, Penn DL. Neurocognitive and social cognitive predictors of interpersonal skill in schizophrenia. Psychiatry Res 2006;143:167-178.

19. Pennebaker JW, Zech E, Rimé B. Disclosing and Sharing Emotion: Psychological, Social, and Health Consequences. In: Stroebe MS, Hansson RO, Stroebe W, Schut H, Editors. Handbook of Bereavement Research: Consequences, Coping, and Care. Washington DC: American Psychological Association; 2001.

20. Swinkels A, Giuliano TA. The measurement and conceptualization of mood awareness: monitoring and labeling one's mood states. Pers Soc Psychol Bull 1995;21:934-949.

21. Rieffe C, De Rooij M. The longitudinal relationship between emotion awareness and internalising symptoms during late childhood. Eur Child Adolesc Psychiatry 2012;21:349-356.

22. Oikawa H, Sugiura M, Sekiguchi A, Tsukiura T, Miyauchi CM, Hashimoto T, et al. Self-face evaluation and self-esteem in young females: an fMRI study using contrast effect. Neuroimage 2012;59:3668-3676.

23. Hu Y, Liao S, Luo W, He W. Effects of self-esteem on self-face recognition: an eye movement study. Open J Soc Sci 2013;1:40-42.

24. Garofalo C, Holden CJ, Zeigler-Hill V, Velotti P. Understanding the connection between self-esteem and aggression: the mediating role of emotion dysregulation. Aggress Behav 2016;42:3-15.

25. Fenigstein A, Scheier MF, Buss AH. Public and private self-conscious- 
ness: assessment and theory. J Consult Clin Psychol 1975;45:522-527.

26. Moss TP, Rosser BA. The moderated relationship of appearance valence on appearance self consciousness: development and testing of new measures of appearance schema components. PLoS One 2012;7:e50605.

27. Tebble NJ, Thomas DW, Price P. Anxiety and self-consciousness in patients with minor facial lacerations. J Adv Nurs 2004;47:417-426.

28. Franzoi SL, Davis MH, Young RD. The effects of private self-consciousness and perspective taking on satisfaction in close relationships. J Pers Soc Psychol 1985;48:1584-1594.

29. LaBrie JW, Hummer JF, Neighbors C. Self-consciousness moderates the relationship between perceived norms and drinking in college students. Addict Behav 2008;33:1529-1539.

30. DaSilveira A, DeSouza ML, Gomes WB. Self-consciousness concept and assessment in self-report measures. Front Psychol 2015;6:930.

31. Salovey P, Mayer JD. Emotional intelligence. Imagin Cogn Pers 1990;9: 185-211.

32. Lee JY, Nam SK, Lee MK, Lee SM. Rosenberg' self-esteem scale: analysis of item-level validity. Korean J Couns Psychother 2009;21(Suppl)1: 173-189.

33. Rosenberg M. Society and the Adolescent Self-Image. Princeton, NJ: Princeton University Press; 1965.

34. Beck AT. Depression: Clinical, Experimental and Theoretical Aspects. New York: Harper and Row; 1967.

35. Diener E, Emmons RA, Larsen RJ, Griffin S. The satisfaction with life scale. J Pers Assess 1985;49:71-75.

36. Johnston MM, Finney SJ. Measuring basic needs satisfaction: evaluating previous research and conducting new psychometric evaluations of the Basic Needs Satisfaction in General Scale. Contemp Educ Psychol 2010;35:280-296.

37. Costa PT, McCrae RR. Normal personality assessment in clinical practice: the NEO Personality Inventory. Psychol Assess 1992;4:5-13.

38. Raven JC. Standard Progressive Matrices. London: H. K. Lewis; 1958.

39. Park JY, Oh JM, Kim SY, Lee MK, Lee CR, Kim BR, et al. Korean Facial Expressions of Emotion (KOFEE). Seoul, Korea: Section of Affect \& Neuroscience, Institute of Behavioral Science in Medicine, Yonsei University College of Medicine; 2011.

40. Campbell JD. Self-esteem and clarity of the self-concept. J Pers Soc Psychol 1990;59:538-549.

41. Jones SC. Self- and interpersonal evaluations: Esteem theories versus consistency theories. Psychol Bull 1973;79:185-199.

42. Ryan RM, Deci EL. Self-determination theory and the facilitation of intrinsic motivation, social development, and well-being. Am Psychol 2000; 55:68-78.

43. Green MC, Kaufman G, Flanagan M, Fitzgerald K. Self-esteem and public self-consciousness moderate the emotional impact of expressive writing about experiences with bias. Pers Indiv Diff 2017;116:212-215.

44. Nezlek JB, Kuppens P. Regulating positive and negative emotions in daily life. J Pers 2008;76:561-580.

45. Cheng CM, Govorun O, Chartrand TL. Effect of self-awareness on negative affect among individuals with discrepant low self-esteem. Self Identity 2012;11:304-316.

46. Keane L, Loades M. Low self-esteem and internalizing disorders in young people-a systematic review. Child Adolesc Ment Health 2017;22: 4-15.

47. Leung CY, Leung GM, Schooling CM. Behavioral problem trajectories and self-esteem changes in relation with adolescent depressive symptoms: a longitudinal study. Soc Psychiatry Psychiatr Epidemiol 2018;53: 673-684.

48. Masselink M, Van Roekel E, Oldehinkel AJ. Self-esteem in early adolescence as predictor of depressive symptoms in late adolescence and early adulthood: the mediating role of motivational and social factors. J Youth Adolesc 2018;47:932-946.

49. Hilsman R, Garber J. A test of the cognitive diathesis-stress model of depression in children: academic stressors, attributional style, perceived competence, and control. J Pers Soc Psychol 1995;69:370-380.

50. Shahar G, Henrich CC. Do depressive symptoms erode self-esteem in early adolescence? Self Identity 2010;9:403-415.

51. Tripković I, Roje R, Krnić S, Nazor M, Karin Ž, Čapkun V. Depression and self-esteem in early adolescence. Cent Eur J Public Health 2015;23: 142-145.

52. Cruz-Sáez S, Pascual A, Wlodarczyk A, Echeburúa E. The effect of body dissatisfaction on disordered eating: the mediating role of self-esteem and negative affect in male and female adolescents. J Health Psychol 2018 [Epub ahead of print].

53. Sheldon KM. The self-determination theory perspective on positive mental health across cultures. World Psychiatry 2012;11:101-102.

54. Molix LA, Nichols CP. Satisfaction of basic psychological needs as a mediator of the relationship between community esteem and wellbeing. Int J Wellbeing 2013;3:20-34.

55. Covington MV. Self-Esteem and Failure in School: Analysis and Policy Implications. In: Mecca AM, Smeiser NJ, Vasconcellos J, Editors. The Social Importance of Self-Esteem. Berkeley: University of California Press, 1989, p.72-124.

56. Boudreault-Bouchard AM, Dion J, Hains J, Vandermeerschen J, Laberge L, Perron M. Impact of parental emotional support and coercive control on adolescents' self-esteem and psychological distress: results of a four-year longitudinal study. J Adolesc 2013;36:695-704.

57. Cai H, Brown JD, Deng C, Oakes MA. Self-esteem and culture: differences in cognitive self-evaluations or affective self-regard? Asian J Soc Psychol 2007;10:162-170. 